\title{
MEDAL AWARDS OF THE ROYAL SOCIETY
}

\section{Copley Medal}

$\mathrm{T}$ HE Copley Medal is awarded to Dr. Oswald Theodore Avery, of the Rockefeller Institute of Now York, for his contributions to knowledge of the chemical basis of the specific properties of bacteria, particularly of the types of the pneumococcus. His researches in this field have appeared in unhurried and orderly sequence over the course of a long and distinguished career, and they have furnished a large and essential constituent of the framework now available for a fundamental science of immunochemistry.

We allow ourselves to claim Avery as Canadian by birth, though with acknowledgment that his life's work has been accomplished in the United States of America, and in the Rockefeller Institute of New York in particular, of which he has held the membership sinco 1913.

It was in 1917 that Dochez and Avery demonstrated that cultures of different strains of the pneumococcus yielded different 'soluble specific substances'. From 1923 onwards appeared a remarkable series of papers by Avery, with Heidelberger and other collaborators, in which it was shown that these specific substances had the nature of complex polysaccharides of highly individual characters. These were present in the regular capsular envelope characteristic of the pneumococcus in its virulent forms ; and each type of such virulent pneumococci, distinguishable by its immunological specificity, was shown to have its own distinct polysaceharide. Each of these reacted, with a like specificity, with the corresponding immune body. Not that these polysaccharides, the soluble specific substances isolated in chemical purity, had antigenic propertios by themselves. It was only when they were artificially linked to proteins foreign to the reacting animal body, or retained their natural linkage with proteins of the bacterial strains producing them, that they elicited, on injection, the appearance in the blood of specific immune substances, causing agglutination or lysis of the corresponding organisms; but, with the immune substances thus evoked, the pure, separated polysaccharides now exhibited the same specific affinities, each forming a precipitate with the corresponding antiserum.

Here, then, in chemically definite form, were separable, prosthetic, combining groups such as Paul Ehrlich had long earlier envisaged and prophetically named 'haptenes'. Here also was one of the principal foundation stones of a great building of immunological chemistry, which, in the hands of Avery's contemporaries and followers, notably in those of a distinguished fellow-member of the Rockefeller Institute, the late Karl Landsteiner, has rapidly included an ever-widening range of studies of artificial and natural antigens.

Meanwhile, in the hands of Avery and his coworkers, knowledge of the specific characters of the pneumococci, and of the manner in which these are acquired, had been moving quietly to a new pinnacle of achievement. They had long ago shown that pneumococei, which, in artificial culture, have lost the capsules endowing them with virulence and containing the specific polysaccharides, have reverted to avirulent non-specific types, growing in the rough, wrinkled colonies characteristic of such defective strains. It had been shown also, by the late Fred Griffith, that such a degenerate, non-specific pneumococcus, from whatever specific type it had its provenance, could be induced by cultivation in a medium prepared from a complete, virulent type to re-acquire a capsule conferring the corresponding specificity. And now, only last year, Avery, with Macleod and McCarty, has been able to isolate and to characterize a chemical principle acting in minute dosage as the specific stimulus to such a transformation. An unencapsulated, avirulent, typeless pneumococcus derived from a specific strain of type II responds to this stimulus by acquiring and retaining the capsule and specific polysaccharide, with the virulence and the cultural characters, of a fully specific strain of type III. Here surely is a change to which, if we were dealing with higher organisms, we should accord the status of a genetic variation; and the substance inducing it-the gene in solution, one is tempted to call it-appears to be a nucleic acid of the desoxyribose type. Whatever it be, it is somothing which should be capable of complete description in terms of structural chemistry.

Avery, a veteran now among investigators, has thus, on the eve of his retirement, attained this new peak of discovery-a fitting climax to a devoted career of such wide influence on the progress of science.

\section{Royal Medals}

A Royal Medal is awarded to Prof. John Desmond Bernal, professor of physics in Birkbeck College, University of London, in recognition of his distinguished contributions to the theory and the applications of X-ray erystal analysis.

Bernal's first important work in this field, published in 1926, was a fundamental study of the basis of the interpretation of X-ray rotation photographs of single crystals; and the methods which he then evolved are still in use. He was largely concerned with the initiative which led to the construction of the "International Crystalline Tables", and himself accepted an important share of the editorial work required. Later he became a leader in the application of X-ray crystallography to the elucidation of the structure of highly complex organic molecules. Organic chemists had encountered difficulties, long insuperable, in formulating a satisfactory structure for the sterols. Here Bernal's crystallographic data, indicating the general shape and dimensional limits of the sterol molecule, supplied a key which opened the way to a convincing reconstruction of the poly. cyclic ramework of cholesterol, ergosterol and calciferol in the first place, and eventually to the structural formulation of a vitally important series of gonadal and adrenal hormones, as these, in due course, were isolated and identified. With admirable enterprise $h_{\Theta}$, with his pupils and associates, proceoded to apply the methods of X-ray crystallography to crystals of some of the simpler proteins, as these became available, such as crystalline pepsin and, later, insulin. Then the discovery, by Stanley, that a plant virus - that causing the 'mosaic' diseases of tobacco-could be obtained in crystalline form, opened the way for Bernal to apply his technique to elucidate the structure of a protein endowed with such paradoxical characters. He was able to describe the virus units as long, rod-like structures, 1,500 A. 
in length by $150 \mathrm{~A}$. in diameter, and with an inner regularity in structure fitting a hexagon lattice and, apparently, consisting of cubical sub-units measuring about $11 \mathrm{~A}$. The readiness with which the long virus units, in a solution, set themselves parallel in a twodimensional lattice provided an explanation for the double refraction and other physieal properties which such solutions of the virus exhibit.

Just before the War, Bernal had published a preliminary note on the structures of hæmoglobin and of ehymotrypsin. Then, like others, he found his activities diverted to the scientific service of the special needs of the nation and its allies at war. The time is not yet for detailed mention of the important special researches he has carried out during the years immediately past, for the Ministry of Civil Defence, the Combined Operations Command, and other Service Departments, which have successively made claims on his special knowledge and ability. We are glad to know that some of his pupils have been able to keep the thread of his more normal scientific activities unbroken over this interval. Biochemistry, as well as the physies of his primary discipline, will expect much now from his resumption of personal participation and leadership in a field which he has made so much his own.

A Royal Medal is awarded to Dr. Edward James Salisbury, director of the Royal Botanic Gardens, Kew, in recognition of his distinguished contributions to plant ecology.

Salisbury's work has had a most important influence in broadening the basis of the study of British plant communities, and in diverting ecological work in Great Britain from an essentially floristic outlook to one in which the habitat and the autecology of individual species have been put in the forefront of interest.

Combining his expert ecological knowledge with a wide acquaintance with cultivated plants and their conditions of growth, Salisbury has shown an exceptional capacity for relating horticultural practices to known physiological and ecological facts, nowhere more strikingly shown than in his "Living Garden". A similar faculty served the country well in the earlier part of the War in connexion with his manifold activities on the Agricultural Research Council.

Making his first contacts with ecology by a detailed study of the oak-hornbeam woods of Hertfordshire, to which he brought some of the experience gained by co-operation with F. W. Oliver in the investigation of the maritime communities at Blakeney Point, Norfolk, Salisbury soon exhibited a more generalized approach to ecological problems. Examples are furnished by his papers on the calcicolous habit and on leaching, which traverse a wide field and open up new points of view. Although somewhat different in seope, the investigation on stomatal frequency, supported by a very large mass of data and published in the Philosophical Transactions in 1927, is essentially directed to clarifying the ecological picture.

In his presidential address to the Ecological Society in 1929 on the biological equipment of species in relation to competition, a topic which is repeatedly touched upon in his earlier work, attention was directed to the almost complete lack of information on the reproductive efficiency of the different species of flowering plants. 'This aspect of a species' equipment had already interested Salisbury for some years, and a number of significant data were given in the course of his addruss. Despite preoccupation with many other matters, he continued actively to accumulate information on reproductive capacity during the subsequent years, collecting data on the seed production of more than 240 British species, which involved the examination of several hundreds of thousands of individual plants. The numerous important conclusions derived from this comprehensive study, which disposes of several fallacies, were published in 1942 in a book, "The Reproductive Capacity of Plants", which constitutes a landmark in the progress of plant ecology.

In addition to his ecological work, Salisbury is known to his botanical colleagues for earlier work on fossil seeds and for important contributions to the distribution of British plants and to the interpretation of floral morphology.

\section{Davy Medal}

The Davy Medal is awarded to Prof. Roger Adams, professor of chemistry in the University of Illinois, in recognition of his distinguished researches in organic chemistry.

Roger Adams is undoubtedly the outstanding organic chemist in the United States at the present time, and his school, the largest and most vigorous of its kind in that country, is of international repute.

His researches, distinguished by great originality and dogged perseverance alike, embrace a remarkably wide field. In a series of brilliant papers he has described the complete elucidation of the structure of gossypol, a highly complex pigment present in cotton seed. This achievement is all the more noteworthy since several other investigators had failed to make much headway in examining this highly sensitive compound. His experimental skill and theoretical insight have, in recent years, led to notable advances in alkaloid chemistry, and in this connexion special mention may be made of his work on the structure of monocrotaline, the toxic constituent of various Crotalaria. Adams has been responsible for pioneoring research in attempts to find synthetic substances antagonistic to the leprosy bacillus and other acid-fast bacteria, and this led him to a detailed study of the chemistry of hydnocarpic and chaulmoogric acids. He has contributed notably to our knowledge of the constituents of Cannabis sativa and $C$. indica (marihuana and hashish), and he has determined the structure of some of their major physiologically active components. His wide interests are clearly exemplified by his researches on stereochemical problems, particularly of the phenomenon of restricted rotation, where his work, especially with diphenyl derivatives, and more recently with aryl olefines and arylamines, is of fundamental importance. Another indication of his versatility is to be found in his detailed studies of catalytic hydrogenation with noble-metal catalysts; the platinic oxide catalyst which he perfected is now universally employed and is known as Adams's catalyst.

While Adams's researches place him in the first rank of contemporary organic chemists, his share in inaugurating the publication of "Organic Syntheses", and "Organic Reactions", immensely valuable standard works of an original type, has ensured that future generations of chemists will ever remain in his debt. 
During the War, Adams's activities have been largely transferred to administrative spheres, where his foresight and organizing ability have enabled him to play an important part in the vast scientific effort of our American colleagues.

\section{Hughes Medal}

The Hughes Medal is awarded to Prof. B. F. J. Schonland, director of the Bernard Price Institute of Geophysics, University of the Witwatersrand, in recognition of his important physical studies of atmospheric electricity and thunderstorms.

Schonland's main contributions to physical research have been in the field of atmospheric electricity, and have dealt particularly with the complex series of electric discharges which constitute a 'stroke' of lightning. Although the study of phenomena associated with thunderstorms could be undertaken under especially favourable natural conditions in his native South Africa, it needed enthusiasm and perseverance to overcome the many technical difficulties encountered in a country in which physical research had not yet been greatly developed, and to bring the research to such definite and illuminating conclusions.

Schonland's early work $(1927,1928)$ dealt with the polarity of thunderclouds; it was established that the negative was below the positive pole of the thundercloud, and that the currents flow in such a direction that they carry negative charges to the earth. Schonland also studied the importance of point discharges (from trees, etc.) in the maintenance of the earth's negative charge. He next used (1934-38) a rotating lens camera of the type devised by the late Sir Charles Boys to photograph and analyse the lightning discharge, and obtained results of great importance for knowledge not only of the nature of the lightning discharge but also of electric discharges in air in a more general sense.

Schonland has taken an active part in the study of cosmic radiation and particularly of the relation between penetrating radiation and thunderstorms; there is a reduction in the intensity of penetrating radiation when thunderclouds are overhead, and this fact provides information as to the total charge carried by penetrating radiation. The occurrence of impulses in a Geiger-Müller counter coincident with discharges in distant thunderstorms shows that some type of penetrating radiation is produced by electrical discharges during thunderstorms. This work on cosmic rays in Schonland's laboratory is of special importance, since few such systematic observations have been continued over long periods in the southern hemisphere.

Schonland has also taken a prominent part in the study of the nature of the 'atmospherics' interfering with wireless transmission, and of the part played by the ionosphere in their structure. These studies have equipped him on the technical side for various military positions he has held during the War; for these, also, his experience in the War of 1914-18 as a captain in the Royal Engineers (Signals) had given him additional equipment. In the War now ended he rose to the charge of an Army Operational Research Group with the rank of brigadier, and later became scientific adviser to the 2lst Army Group commanded by Field-Marshal Montgomery; and now General Smuts, as Prime Minister of the Union of South Africa, has claimed Dr. Schonland's services as his adviser on the promotion and development of scientific research in his own country.

\section{BOSE RESEARCH INSTITUTE, CALCUTTA}

\section{ANNUAL REPORTS}

$\mathrm{T}$ HE annual report of the governing body of the Bose Research Institute, Calcutta, for the year 1943-44 refers to the way in which the growing difficulty in securing photographic materials, glass goods and chemicals, especially organic chemicals, hampers the work of the Institute. With grants received from the Board of Scientific and Industrial Research, schemes of research on the setting up of a powerful generator of ultrasonic waves and on testing and cutting quartz plates for the radio industry have been undertaken, and with grants from the Bengal Immunity Co., Ltd., schemes for applied research in microbiology and on the vernalization of paddy in Bengal are also being undertaken. Among the investigations referred to in the report are those on cosmic rays, and an important paper on the Wilson chamber study of meson spectra has been published in the Transactions of the Institute, results obtained in the laboratory agreeing with the predictions of the theory of Moller and Rosenfeld. The investigations with the Wilson chamber photographs are being continued to verify and extend the results obtained with lead absorbers with other absorbers like iron and carbon. Other physical researches were concerned with nuclear fission, the nuclear isomerization of $\mathrm{Br}^{80}$, the construction of a neutron generator and an ultrasonic generator. A valve tube amplifier circuit has been assembled for measuring dielectric potentials set up in plant tissues, either simultaneously or under stimulation, and the transmission of excitation in Nitella and Chara is being studied.

An important part of the activity of the Biochemistry Department is the preparation of biologically active compounds required for physiological and microbiological studies of plants, including such substances as glucose 1-phosphate, adenylic and nucleic acids, cis-and trans-crocetin dimethyl ester, crocin and picrocrocin, and it has been possible to isolate cis- and trans-crocetin dimethyl ester, crocin and saffranol from saffron obtained from Kashmir, the yields of these compounds from the Indian variety being higher than those obtained by Kuhn and Karrer from saffron from Spain, the south of France and Asia Minor. A series of manurial experiments has been conducted with jute plants, and further investigations completed on the effect of the $p H$ values of nutrient solutions on the growth of jute plants.

In the Biology Department preliminary experiments on the auxin effect on Desmodium gyrans indicate that at low concentrations the auxin is a respiratory catalyst for some substrates present in the cells of Desmodium gyrans, and that malate is one of the substrates on which this auxin acts. Different concentrations of synthetic auxin were tried to produce roots in gootes and cuttings of cinchona, indolylbutyric acid being the most effective in the formation of roots. The study of the growth of the root is being carried out by an automatic recording device previously constructed in the Institute. In the Microbiology Section, studies of the diseases of tropical fruits and vegetables are being undertaken to discover the nature of the relation between the parasites and their specific hosts, nature of infection, and mechanism of rotting, factors influencing the susceptibility of fruits and control of wastage. A 